
\title{
25 Research Suare \\ Tight association of autophagy and cell cycle in leukemia cells
}

\section{Alena Gschwind \\ Jena University Hospital: Universitatsklinikum Jena \\ Christian Marx}

Leibniz Institute on Aging - Fritz Lipmann Institute: Leibniz Institut fur Altersforschung - Fritz-Lipmann Institut eV

\section{Marie D. Just}

Jena University Hospital: Universitatsklinikum Jena

\section{Paula Severin}

Jena University Hospital: Universitatsklinikum Jena

\section{Hannah Behring}

Jena University Hospital: Universitatsklinikum Jena

\section{Lisa Marx-Blümel}

Jena University Hospital: Universitatsklinikum Jena

\section{Sabine Becker}

Jena University Hospital: Universitatsklinikum Jena

\section{Linda Rothenburger}

Leibniz Institute on Aging - Fritz Lipmann Institute: Leibniz Institut fur Altersforschung - Fritz-Lipmann Institut eV

\section{Martin Förster}

Jena University Hospital: Universitatsklinikum Jena

James F. Beck

Jena University Hospital: Universitatsklinikum Jena

Jürgen Sonnemann ( $\nabla$ juergen.sonnemann@med.uni-jena.de)

Jena University Hospital: Universitatsklinikum Jena https://orcid.org/0000-0003-2993-9161

\section{Research}

Keywords: Autophagy, cell cycle, cell sorting, Cyto-ID, DRAQ5, metabolic analysis

Posted Date: December 9th, 2021

DOI: https://doi.org/10.21203/rs.3.rs-1106620/v1 
License: (c) (i) This work is licensed under a Creative Commons Attribution 4.0 International License. Read Full License

Version of Record: A version of this preprint was published at Cellular \&amp; Molecular Biology Letters on April 5th, 2022. See the published version at https://doi.org/10.1186/s11658-022-00334-8. 


\section{Abstract}

\section{Background}

Autophagy plays an essential role in maintaining cellular homeostasis and in the response to cellular stress. Autophagy is also involved in cell cycle progression, yet the relationship between these processes is not clearly defined.

\section{Results}

In exploring this relationship, we observed that the inhibition of autophagy impaired the G2/M phasearresting activity of etoposide but enhanced the $\mathrm{G} 1$ phase-arresting activity of palbociclib. We further investigated the connection of basal autophagy and cell cycle by utilizing the autophagosome tracer dye Cyto-ID in two ways. First, we established a double-labeling flow-cytometric procedure with Cyto-ID and the DNA probe DRAQ5, permitting the cell cycle phase-specific determination of autophagy in live cells. This approach demonstrated that different cell cycle phases were associated with different autophagy levels: G1 phase cells had the lowest one and G2/M phase cells had the highest one. Second, we developed a flow-cytometric cell sorting procedure based on Cyto-ID that separates cell populations into fractions with low, medium and high autophagy. Cell cycle analysis of Cyto-ID-sorted cells confirmed that the high autophagy fraction contained a much higher percentage of $\mathrm{G} 2 / \mathrm{M}$ phase cells than the low autophagy fraction. Beyond that, Cyto-ID-based cell sorting proved also to be useful for assessing other autophagy-related processes: extracellular flux analysis revealed metabolic differences between the cell populations, with higher autophagy being associated with higher respiration, higher mitochondrial ATP production and higher glycolysis.

\section{Conclusion}

This work sheds new light on the interrelation of autophagy and cell cycle by establishing a novel cell sorting technique based on Cyto-ID.

\section{Introduction}

Macroautophagy (henceforth autophagy) is a cytoprotective mechanism critically involved in physiological and pathophysiological processes [1-3]. It is a constitutive activity for bulk degradation of damaged, aged or surplus organelles and aberrant protein aggregates, thus preserving cellular homeostasis. It also serves as an inducible response to stress insults, allowing cells to cope, e.g., with starvation, hypoxia or oxidative damage. The autophagic pathway comprises the sequestration of cytoplasmic constituents through the formation of double-membrane autophagosomes that eventually fuse with lysosomes to create autolysosomes $[1,4]$. The latter degrade their cargo, thereby not only removing potentially harmful elements but also facilitating the reutilization of building blocks, e.g., for protein synthesis, gluconeogenesis and energy production. At the molecular level, autophagy is regulated by the coordinated action of autophagy-related (ATG) genes [1, 4]. Autophagy is implicated in many 
human diseases and its therapeutic targeting has gained traction in recent years particularly for the treatment of cancer [1-7].

Autophagy, therefore, is a fundamental activity in eukaryotic cells and it is hence hardly surprising that it is also involved in cell cycle progression and regulation [8-11]. Autophagy and cell cycle are linked by a variety of mechanisms that are governed by common signaling pathways. Particular mention here deserves mTORC1 signaling, which plays a crucial role in controlling both autophagy and cell growth [12, 13]: mTORC1 promotes proliferation and suppresses autophagy, pointing to an inverse relationship between these cellular processes [8-11]. This concept is further reinforced by observations that cell cyclepromoting protein kinases, such as cyclin-dependent kinases (CDKs), prevailingly impinge on the autophagic pathway [14]. Vice versa, both endogenous and pharmacological inhibitors of CDKs have been reported to increase autophagy [15-17]. Autophagy and cell cycle are additionally interconnected through the DNA damage response that entails the suspension of cell cycle progression as well as the stimulation of autophagy; the former allows time for proper DNA repair while the latter seconds the DNA repair machinery [18-21]. DNA damage-mediated autophagy and cell cycle responses are prominently intertwined by the tumor suppressor protein p53 [22, 23].

A possible interdependence of cell cycle phase and autophagy has been addressed in several studies. While the findings widely agree that autophagy is differentially regulated during the cell cycle, they diverge as to which cell cycle phase exhibits highest autophagic activity. The majority of reports demonstrated a link of higher autophagy levels to interphase [24-26], and autophagy inducers as diverse as starvation, the mTORC1 inhibitor sirolimus (also known as rapamycin), ABT-737, tunicamycin and lithium elicited autophagy preferentially in the $\mathrm{G} 1$ and S phases of the cell cycle [27]. Likewise, G1 cell cycle arrest mediated by drugs such as celecoxib, metformin, magnolin and dimethyl fumarate was found to be associated with elevated autophagy [28-31]. Yet a couple of papers reported highly active autophagy in mitosis [32-35], and some others related autophagy activation to a halt of the cell cycle in $\mathrm{G} 2$ or mitosis. Concurrent induction of autophagy and $\mathrm{G} 2 / \mathrm{M}$ cell cycle arrest was observed in response to agents like plumbagin, resveratrol, artesunate and a boswellic acid analog [36-39] as well as after ionizing radiation $[40,41]$. In addition, removal of damaged mitochondria by autophagy can be associated with a cell cycle arrest in G2/M [42]. By contrast, the notion of a coordinated interplay of autophagy and cell cycle was challenged altogether by a study which showed that starvation- and sirolimus-induced accumulation of autophagosomes occurred at all stages of the cell cycle [43].

All told, the relation between autophagy and cell cycle is far from being resolved and further work is required to understand their interconnection. We, therefore, set out to relook at the interaction of autophagy and cell cycle at its basis. To this end, we took advantage of Cyto-ID, a fluorescent dye for selective staining of autophagosomes [44-46], in two ways: First, we conducted double-labeling flow cytometry with Cyto-ID and the live-cell-permeant DNA marker DRAQ5, allowing for simultaneous monitoring of autophagy and cell cycle phases. Second, we developed a Cyto-ID-based flow-cytometric cell sorting procedure that separates cell populations into subgroups with low, medium and high autophagy suited for downstream culturing of separated cells. Our analyses revealed a clear association 
between differences in constitutive autophagy and cell cycle phase - cells with low autophagy systematically predominated in the G1 phase and cells with high autophagy in the G2/M phase.

\section{Materials And Methods}

\section{Cell culture}

Jurkat and MOLM-13 cells were purchased from the DSMZ (Braunschweig, Germany). Cells were cultured in RPMI 1640 medium with stable L-glutamine (Lonza, Cologne, Germany) supplemented with $10 \%$ (Jurkat) or $20 \%$ (MOLM-13) FCS (Capricorn Scientific, Ebsdorfergrund, Germany), 100 units $/ \mathrm{ml}$ penicillin $\mathrm{G}$ sodium salt and $100 \mu \mathrm{g} / \mathrm{ml}$ streptomycin sulfate (Lonza). Cells were maintained in a humidified atmosphere at $37{ }^{\circ} \mathrm{C}$ and $5 \% \mathrm{CO}_{2}$. Cells were tested to be negative for mycoplasma with the qPCR Mycoplasma Test Kit from Applichem (Darmstadt, Germany).

\section{Treatment of cells}

Cells were seeded in 12-well tissue culture plates at 150,000 (Jurkat) or 200,000 (MOLM-13) cells/well. To induce autophagy, cells were exposed to $0.1-0.5 \mu \mathrm{M}$ etoposide (provided by the Jena University Hospital Pharmacy) for 6-48 h or to 25-400 nM palbociclib (MedChemExpress, Monmouth Junction, NJ, USA) for $48 \mathrm{~h}$. To inhibit autophagy, cells were exposed to $2 \mathrm{mM}$ 3-methyladenine (3-MA; Biomol, Hamburg, Germany) for $24 \mathrm{~h}$ or $48 \mathrm{~h}$, or to 10 or $25 \mu \mathrm{M}$ chloroquine (CQ; Enzo Life Sciences, Lörrach, Germany) for $1-48 \mathrm{~h}$.

\section{Flow-cytometric analysis of cell death}

Cell death was determined by propidium iodide $(\mathrm{PI})$ uptake analysis. After harvesting, cells were incubated in $2 \mu \mathrm{g} / \mathrm{ml} \mathrm{PI}$ (Sigma-Aldrich, Deisenhofen, Germany) in PBS at $4{ }^{\circ} \mathrm{C}$ immediately before analysis. 10,000 cells per sample were analyzed on a BD (Heidelberg, Germany) FACSCanto II using BD FACSDiva software. Data were gated based on forward light scatter area (FSC-A) versus sideward light scatter area (SSC-A) to exclude debris.

\section{Flow-cytometric analysis of autophagy}

Cells were stained with Cyto-ID (Enzo Life Sciences) basically according to the manufacturer's recommendations. In brief, cells were washed with indicator-free medium (IFM), consisting of phenol redfree RPMI 1640 medium (Capricorn Scientific) containing $5 \%$ FCS and 2 mM L-glutamine (Lonza), and incubated in Cyto-ID at a dilution of 1:1000 in IFM for 30 min at $37^{\circ} \mathrm{C}$. After washing and resuspension in IFM, PI was added to a final concentration of $2 \mu \mathrm{g} / \mathrm{ml}$ PI immediately before analysis. 10,000 cells per sample were analyzed on a FACSCanto II using FACSDiva software. Data were gated based on FSC-A versus SSC-A to exclude debris and further gated on PI-negative populations to exclude dead cells. 
Protocol I, analysis of Pl-stained ethanol-fixed cells: Cells fixed in $70 \%$ ethanol at $-20{ }^{\circ} \mathrm{C}$ for at least $2 \mathrm{~h}$ were washed and resuspended in PBS containing $1 \%$ glucose, $50 \mu \mathrm{g} / \mathrm{ml}$ RNase A (Sigma-Aldrich) and 50 $\mu \mathrm{g} / \mathrm{ml} \mathrm{Pl}$, and incubated under light exclusion for $45 \mathrm{~min}$ at $4{ }^{\circ} \mathrm{C}$. Protocol II, analysis of DRAQ5-stained live cells, applied only in Cyto-ID/DRAQ5 double-labeling analysis: Cells were adjusted to a density of 400,000 cells/ml and incubated with $10 \mu$ M DRAQ5 (Thermo Fisher Scientific, Dreieich, Germany) in IFM for 15 min at $0{ }^{\circ} \mathrm{C}$ (i.e., DRAQ5 staining was carried out subsequent to Cyto-ID staining). In both methods, 20,000 cells per sample were analyzed on a FACSCanto II. Data were gated based on FSC-A versus SSC-A to exclude debris and on FSC-A versus FSC width (FSC-W) to exclude aggregates. The different cell cycle phases were quantified using FACSDiva software; cells with sub-G1 DNA content were included in some Protocol I analyses.

\section{Flow-cytometric cell sorting on the basis of Cyto-ID staining}

$1 \times 10^{7}$ cells were stained with Cyto-ID as described, resuspended in $1 \mathrm{ml} \mathrm{IFM}$, filtered through $35-\mu \mathrm{m}$ mesh and incubated with $1 \mu \mathrm{M}$ Sytox Blue (Thermo Fisher Scientific) immediately before sorting. Cells were sorted into three subpopulations of approximately equal number according to the Cyto-ID fluorescence intensity, i.e., into populations with low, medium and high Cyto-ID fluorescence. To minimize the starvation period during the sorting procedure, the collection tubes were prefilled with $1 \mathrm{ml}$ of complete growth medium or IFM, depending on the subsequent analysis. Sorting was done on a BD FACSAria Fusion at $45 \mathrm{psi}$ using an $85 \mu \mathrm{M}$ nozzle at $4^{\circ} \mathrm{C}$. Debris and aggregates were excluded from the sorting using a sequential gating strategy relying on FSC-A versus SSC-A followed by FSC height (FSC-H) versus FSC-W and SSC height (SSC-H) versus SSC width (SSC-W). Dead cells were excluded by gating on Sytox Blue-negative cells. The dot plots shown in Figure S4 were created with FlowJo version 10.5.0 (TreeStar, Ashland, OR, USA). For downstream culturing, cells were seeded in 12-well tissue culture plates at 100,000 cells/well.

\section{Flow-cytometric cell sorting on the basis of DRAQ5 staining}

$2 \times 10^{6}$ cells were stained with DRAQ5 as described, resuspended in $1 \mathrm{ml} \mathrm{IFM}$, filtered through $35-\mu \mathrm{m}$ mesh and incubated with $1 \mu \mathrm{M}$ Sytox Blue immediately before sorting. Cells were sorted into G1, S and G2/M phase fractions. Sorting was done on a BD FACSAria Fusion at 45 psi using an $85 \mu \mathrm{M}$ nozzle at $4{ }^{\circ} \mathrm{C}$. Debris and aggregates were excluded from the sorting using a sequential gating strategy relying on FSCA versus SSC-A followed by FSC-H versus FSC-W and SSC-H versus SSC-W. Dead cells were excluded by gating on Sytox Blue-negative cells. Cells were subjected to analyses immediately after sorting since DRAQ5's genotoxicity precludes culturing of DRAQ5-exposed cells [47].

\section{Real-time RT-PCR}

Total RNA was isolated using the Peqgold Total RNA Kit including DNase digestion (Peqlab, Erlangen, Germany). RNA was transcribed into cDNA using the Omniscript RT Kit (Qiagen, Hilden, Germany). Realtime PCR was conducted on a Thermo Fisher Scientific Applied Biosystems 7900HT Real-Time PCR system. Target gene expression levels were normalized to B2M expression levels. Reactions were done in 
duplicate using Applied Biosystems Gene Expression Assays (ULK1: Hs00177504_m1, MAP1LC3B: Hs00797944_s1, CCNB1: Hs01030099_m1, PLK1: Hs00983227_m1, B2M: Hs00187842_m1) and Universal PCR Master Mix. All procedures were conducted as per the manufacturers' instructions. The relative gene expressions were calculated by the $2\left(^{-\Delta \Delta C t}\right)$ method.

\section{Immunoblotting}

Lysates were prepared either immediately after sorting or after 1-h cultivation of sorted cells. 350,000 cells of each fraction were centrifuged at $250 \times g$ for 5 min and resuspended in $35 \mu$ RIPA buffer [50 mM Tris/HCl (pH 8.0), 150 mM NaCl, 1 mM EDTA, 1 \% Triton X-100, 1 \% sodium deoxycholate and $0.1 \%$ SDS] supplemented with protease and phosphatase inhibitor cocktails (Sigma-Aldrich), followed by brief sonication ( 5 cycles with $30 \mathrm{~s}$ on and $30 \mathrm{~s}$ off with high intensity at $4{ }^{\circ} \mathrm{C}$ ) in a Bioruptor Plus (Diagenode, Seraing, Belgium) sonication device. All samples were diluted 1:6 in 6x SDS-sample buffer (35\% $\beta$ mercaptoethanol, 350 mM Tris/ $\mathrm{HCl}$ pH 6.8, 30 \% glycerol, 10 \% SDS, 0.25 \% bromophenol blue) and heated at $95^{\circ} \mathrm{C}$ for $7 \mathrm{~min}$. 10-20 $\mu \mathrm{l}$ sample volume per lane were separated by standard SDS-PAGE on 712-15\% three-step gels and electrophoretically transferred onto PVDF membranes (Bio-Rad, Munich, Germany). After blocking in TBS ( $\mathrm{pH} 7.25$ ) containing $5 \%$ dry milk and $0.05 \%$ Tween-20, the membranes were incubated with primary antibodies overnight at $4{ }^{\circ} \mathrm{C}$. Antibodies used: LC3B (1:1000; Cell Signaling Technologies, Frankfurt on the Main, Germany, 2775S), Cyclin B1 (1:1000; BD, 554176) and pS10-H3 (1:1000; Merck Millipore, Darmstadt, Germany, 06-570). Equal loading of protein was verified by using $\beta-$ actin antibodies (1:10,000; Sigma-Aldrich, A5441). Peroxidase-conjugated anti-mouse (1:10,000; 52200341) or anti-rabbit IgG (1:5000; Seracare, Milford, MA, USA, 5220-0336) was used as secondary antibodies followed by detection of specific signals using Pierce ECL Western Blotting substrate (Thermo Fisher Scientific) and WesternBright Sirius HRP substrate (Advansta, San Jose, CA, USA) on an Amersham Imager 600 (GE Healthcare, Munich, Germany).

\section{Metabolic analysis}

Cell Mito Stress Tests were done in sextuplicates using a Seahorse XFe96 Extracellular Flux Analyzer (Agilent Technologies, Waldbronn, Germany). Following cell sorting, cells were switched to Seahorse XF RPMI medium (pH preadjusted to 7.4) supplemented with $10 \mathrm{mM}$ glucose, $2 \mathrm{mM}$ L-glutamine (SigmaAldrich), 1 mM sodium pyruvate and 10 \% FCS (Thermo Fisher Scientific). Cells were plated at 70,000 cells/well in Seahorse XF96 cell culture microplates and left to equilibrate for $1 \mathrm{~h}$ in a $\mathrm{CO}_{2}$-free incubator at $37^{\circ} \mathrm{C}$. Oxygen consumption rate (OCR) and extracellular acidification rate (ECAR) were determined according to Seahorse protocols with some modifications. In brief, OCR (pmoles/min) and ECAR $(\mathrm{mpH} / \mathrm{min})$ were measured 3 times each at the baseline and after sequential injections of $2 \mu \mathrm{M}$ oligomycin (Abcam, Berlin, Germany), $15 \mu \mathrm{M}$ 2,4-dinitrophenol and $2 \mu \mathrm{M}$ antimycin A (Sigma-Aldrich) in cycles of 3 min mixing and 3 min measuring. The datasets were analyzed with Wave software (Agilent Technologies). ATP production was calculated by subtracting the average of the three OCR values after oligomycin injection from the average of the three OCR values before oligomycin injection. 


\section{Statistical analysis}

Statistical significance of differences between experimental groups was determined using paired twotailed Student's $t$ test. The threshold of significance was defined as $P<0.05$ without further differentiation. Statistical difference was only assessed where relevant; the lack of an asterisk or a hash mark thus does not imply lack of significant difference.

\section{Results}

\section{The autophagy inhibitor 3-MA prevents etoposide-mediated cell cycle effects}

This study aimed at shedding light on the interaction of autophagy and cell cycle progression. To begin with, we applied etoposide [48], a topoisomerase II inhibitor that induces both G2/M cell cycle arrest [49, 50] and autophagy [51-53]. Because trypsin treatment can provoke considerable cell physiological alterations [54] potentially also interfering with autophagy, we employed suspension cells to obviate the necessity of enzyme treatment for cell harvest. We used Jurkat and MOLM-13 leukemia cells, cell lines with different p53 status, a feature that may impact on the cell cycle and the autophagy response [22, 23]; Jurkat cells have mutant p53 and MOLM-13 cells have wild-type p53 $[55,56]$. We exposed the cells to etoposide alone and in conjunction with 3-MA, one of the most commonly used autophagy inhibitors [57], and performed cell cycle analysis of PI-stained ethanol-fixed cells (Figure 1). Etoposide alone caused a concentration-dependent accumulation of Jurkat cells in the G2/M phase and a biphasic response in MOLM-13 cells; in the latter, increasing concentrations of etoposide produced first an accumulation of cells in the $\mathrm{G} 1$ phase and then in the G2/M phase. These effects were thwarted by 3-MA, providing initial evidence of an interrelationship between autophagy and cell cycle.

\section{G2/M phase cells have higher autophagy than G1 phase cells}

We replicated these analyses in live cells using the supravital DNA dye DRAQ5 and obtained similar results (Figure S1). To simultaneously assess cell cycle distribution and autophagy, we costained cells with DRAQ5 and Cyto-ID, thus enabling the cell cycle phase-specific monitoring of autophagy (Figure 2A). Figure 2B shows that etoposide induced a concentration-dependent increase in Cyto-ID fluorescence indicative of autophagy activation. 3-MA predictably blocked the Cyto-ID fluorescence increase.

As with LC3 immunoblotting for the detection of autophagy [57], Cyto-ID fluorescence alone is insufficient for the estimation of autophagic flux. Yet the use of agents that prevent autophagosome turnover, such as CQ, can provide evidence of alterations in autophagic flux; an additive or supra-additive effect of combined treatment with the putative autophagy inducer and the autophagosome turnover blocker is indicative of enhanced autophagic flux [57]. Accordingly, we compared etoposide alone to etoposide plus CQ. The combination treatment resulted in a supra-additive effect relative to treatment with etoposide or CQ alone in both cell lines (Figure S2). 
Cyto-ID/DRAQ5 double staining also revealed that in untreated cells, i.e., cells with basal autophagy, different cell cycle phases were associated with different autophagy levels: the highest one was found in G2/M phase cells and the lowest one in G1 phase cells (Figure $2 \mathrm{C}$ ). This difference was also evident, at a lower level, in 3-MA-treated cells. Furthermore, treatment with etoposide led to autophagy activation in all cell cycle phases though, strongest activation arose in G2/M phase cells. The effects occurred in both p53 wild-type and mutant cells, indicating that p53 was not critically involved.

To complement these data with the evaluation of a G1 phase blocker, we conducted similar analyses using the CDK4/6 inhibitor palbociclib that induces $\mathrm{G} 1$ cell cycle arrest [58] along with autophagy [16, 17]. Palbociclib treatment predictably increased the fraction of Jurkat and MOLM-13 cells in the G1 phase (Figure 3A). Coexposure to the autophagy inhibitors 3-MA or CQ further increased the percentage of G1 phase cells, thus enhancing palbociclib's cell cycle-arresting activity. Palbociclib evoked also a rise in Cyto-ID fluorescence that, however, became evident in Jurkat cells only upon cotreatment with CQ (Figure 3B). In any case, the G2/M phase cells again showed the strongest Cyto-ID fluorescence throughout the measurements (Figure 3C).

To gain additional insight into the interplay of autophagy and cell cycle phase, we assessed the effect of etoposide over a time course of 12-24 h in Jurkat cells (Figure 4A). For a close analysis of the data, we grouped the cell populations into quintiles according to their Cyto-ID fluorescence at each time point (Figure 4B and Figure S3A). We generated cell cycle profiles of each quintile of cells, demonstrating that autophagy level and cell cycle phase were unambiguously associated - the higher the autophagy level, the more cells in the G2/M phase (Figure S3B presents the cell cycle histograms at baseline, i.e., for untreated cells with basal autophagy, and after a 24-h exposure to $0.2 \mu \mathrm{M}$ etoposide, and Figure $4 \mathrm{C}$ presents the quantifications for all conditions). For example, at baseline, of cells with lowest autophagy, $82.8 \pm 2.02 \%$ were in $\mathrm{G} 1$ and $8.5 \pm 1.00 \%$ in G2/M phase, while of cells with highest autophagy, $19.9 \pm$ $2.58 \%$ were in $\mathrm{G} 1$ and $67.0 \pm 4.49 \%$ in $\mathrm{G} 2 / \mathrm{M}$ phase.

\section{Cyto-ID-based cell sorting}

So far, our findings clearly pointed to particularly high autophagy in G2/M phase cells. To test this further, we established a flow-cytometric cell sorting method for the separation of cells with low, medium and high basal autophagy (henceforth referred to as Aut ${ }^{\mathrm{LO}}$, Aut ${ }^{\mathrm{ME}}$ and $\mathrm{Aut}^{\mathrm{HI}}$, respectively) on the basis of CytoID fluorescence (the gating strategy for Cyto-ID-based cell sorting is shown Figure S4). We beforehand checked critical parameters for Cyto-ID-based cell sorting: Cyto-ID was not cytotoxic over a sustained incubation of $4 \mathrm{~h}$ (Figure S5A); at $4{ }^{\circ} \mathrm{C}$, the Cyto-ID fluorescence did not change over the measurement period of $90 \mathrm{~min}$, whereas it rapidly declined at room temperature and even more so at $37^{\circ} \mathrm{C}$ (Figure S5B); the sorting procedure per se had no effect on the cells' autophagy (Figure S5C). We also checked the possibility of a mere association of Cyto-ID fluorescence intensity with cell size and detected only minute differences in size between cells with low, medium and high Cyto-ID fluorescence (Figure S5D), thus excluding the possibility that higher Cyto-ID fluorescence was simply due to potentially higher autophagosome numbers in bigger cells. 
LC3B immunoblots confirmed the distinct autophagy levels of the three fractions (Figure 5A). Upon assessing the stability of the different autophagy levels of the three populations, we found that although they tended to converge over time, differences persisted for at least $24 \mathrm{~h}$ after sorting (Figure 5B). As a first step toward a differential characterization of Aut ${ }^{\mathrm{LO}}$, Aut ${ }^{\mathrm{ME}}$ and $\mathrm{Aut}^{\mathrm{HI}}$, we conducted gene expression analyses. Albeit autophagy is basically a cytoplasmic pathway, it can also be subject to transcriptional regulation [59-61]. To examine whether variations in basal autophagy were reflected by differences in the expression of ATG genes, we determined the relative mRNA abundance of two ATG genes that have particularly often shown transcriptional regulation, the LC3B-coding gene MAP1LC3B and ULK1 [60]. While the former was equally expressed in the three populations of both cell lines, the expression level of the latter displayed an association with the level of autophagy in MOLM-13 cells, i.e., ULK1 was expressed in the order Aut ${ }^{\mathrm{HI}}>\mathrm{Aut}^{\mathrm{ME}}>\mathrm{Aut}{ }^{\mathrm{LO}}$ (Figure 5C). Remarkably, differences in ULK1 expression were still evident $24 \mathrm{~h}$ after sorting, although to a reduced degree (Figure 5D). It should be noted, however, that ULK1 was uniformly expressed in the three fractions of Jurkat cells, demonstrating that autophagy variability was not strictly associated with altered ULK1 expression.

\section{Cells with high autophagy are more metabolically active than cells with low autophagy}

Autophagy and cellular metabolism are intimately linked [62-64]. So to further characterize the Cyto-IDsorted cell populations, we performed metabolic measurements with a Seahorse XFe96 Analyzer [65]. Using the Seahorse Cell Mito Stress Test, we measured key mitochondrial functions by determining the OCR of cells utilizing sequential reagent injections (Figure S6). We recorded higher basal respiration and higher ATP production in Aut ${ }^{\mathrm{HI}}$ compared with Aut ${ }^{\mathrm{ME}}$ and $\mathrm{Aut}^{\mathrm{LO}}$ in both cell lines (Figure $6 \mathrm{~A}$ ). In parallel, we measured the ECAR to assess the glycolytic production of lactate $/ \mathrm{H}^{+}$, revealing that baseline glycolysis was also highest in Aut ${ }^{\mathrm{HI}}$ (Figure 6B). Mapping the OCR of basal respiration versus glycolysisrelated ECAR illustrates that higher autophagic activity was strictly associated with higher bioenergetic activity in the two cell lines (Figure 6C).

\section{Cells with high autophagy are preferentially in the G2/M phase}

To return to our primary purpose, the elucidation of the relationship between autophagy and cell cycle, we subjected the Cyto-ID-sorted cell populations to cell cycle analyses. Our findings matched those presented in Figure 4: less than $10 \%$ of Aut ${ }^{\mathrm{LO}}$ but about $40 \%$ of Aut ${ }^{\mathrm{HI}}$ were found in the G2/M phase in both Jurkat and MOLM-13 cells (Figure 7A-B). We attempted to further substantiate the evidence for this interaction by real-time RT-PCR and immunoblot analysis of cell cycle regulated genes. CCNB1 (encoding cyclin B1) and PLK1 were used as marker genes and cyclin B1 and phospho-histone (Ser10) H3 (pS10-H3) were used as marker proteins of cells in the G2/M phase of the cell cycle [66]. Figure 7C-D shows that G2/M marker abundance was systematically increased in $\mathrm{Aut}^{\mathrm{HI}}$.

We also adopted a reciprocal approach to address the interrelation between autophagy and cell cycle by sorting of cells into G1, S and G2/M fractions on the basis of their DRAQ5 signal followed by Cyto-ID 
staining. Again, the G1 phase was associated with lowest autophagy and, vice versa, the G2/M phase was associated with highest autophagy (Figure S7).

\section{Discussion}

Here we explored the relationship between basal autophagy and cell cycle in leukemia cells. As general bottom line, we showed that the G2/M phase was linked to highest autophagy. The evidence for this conclusion came from two experimental approaches: the simultaneous monitoring of autophagy and cell cycle, and the sorting of cells into populations with distinct autophagy levels.

As our first evidence for the interdependence of autophagy and cell cycle, however, we observed that the autophagy inhibitor 3-MA abrogated the etoposide-induced accumulation of G2/M phase cells. This observation is in line with studies reporting that 3-MA or CQ prevented other compounds from eliciting cell cycle arrest [30, 37-39]. More importantly, the exposure to 3-MA alone increased the proportion of cells in the $\mathrm{G} 1$ phase (see Figure 1 and Figure $\mathrm{S} 1$ at $0 \mu \mathrm{M}$ etoposide), indicative of a $\mathrm{G} 1$ cell cycle block. This result suggests that a certain minimum autophagic activity is essential for cell cycle progression. A similar conclusion has been reached upon investigating ULK1/ATG13 double knockout cells [35]. Our examination of palbociclib effects additionally supports this conclusion, since it showed that although the induction of a G1 phase arrest was accompanied by increased autophagy, preventing the latter further fueled the former. An accessory implication of this finding with potential clinical relevance is that the inhibition of autophagy might enhance the cytostatic action of CDK4/6 inhibitors [58].

To deepen our understanding of the interrelation between basal autophagy and cell cycle, we first established a cell cycle phase-specific delineation of autophagy by Cyto-ID/DRAQ5 double-staining analysis. This approach demonstrated strongest Cyto-ID fluorescence in G2/M phase cells. This observation is in keeping with a study that detected increased levels of LC3B in G2/M phase cells by flow cytometric analysis of immunofluorescent-labeled LC3B [67]. Our results were substantially the same in both p53 mutant Jurkat and p53 wild-type MOLM-13 cells, indicating that p53 did not play a major role here, while in a study on colon cancer cells, p53 was shown to affect autophagy in a cell cycle-dependent manner [68]. In exploring the functional consequences of cell-to-cell differences in basal autophagy, Gump et al. found that the stochastic variability in autophagic activity determined the apoptotic response to death ligands [69]. Our data show that the range of cell-to-cell differences in autophagy was narrower in the individual cell cycle phases than in the total cell population, suggesting that the cell populationintrinsic heterogeneity in autophagy is in part accounted for by the cell cycle phase.

We second established a flow cytometry method for the separation of cells based on their differences in basal autophagy. We are aware of only one previous approach for autophagy-based sorting of cells: Gump et al. employed cells constitutively expressing a tandem labeled fluorescent reporter (mCherryEGFP-LC3B), where a high red/green fluorescent ratio indicates cells with enhanced autophagic flux [69, 70]. We used Cyto-ID staining that, not directly measuring autophagic flux though, entails two advantages. First, cells do not undergo any other manipulation than Cyto-ID staining prior to sorting. The 
method thus avoids the potential pitfalls arising from genetic manipulations in general - which can introduce genetic variation even when considered to be neutral [71] - and in particular those caused by ectopic expression of chimeric GFP-LC3B [57]. Second, since our procedure does not involve the generation of stable reporter cell lines, it can readily be applied to other cell lines, making it possible to address autophagy-related questions in different cellular systems without much effort. We tested the essential prerequisites for the suitability of Cyto-ID for cell sorting (see Figure S5). Its temperaturedependent fluorescence intensity is of particular relevance: its robust stability at $4{ }^{\circ} \mathrm{C}$ for at least $90 \mathrm{~min}$ permits sorting (which may take an hour to complete), while its rapid decay at $37^{\circ} \mathrm{C}$ allows Cyto-ID measurements at later time points without risk of interference from the Cyto-ID used for sorting.

The first noteworthy result obtained from cell sorting was the differential expression of ULK1 in the fractions of MOLM-13 cells. Gump et al. concluded from their investigations that differences in gene expression were not responsible for differences in autophagy [69], whereas our observation suggests that fluctuations in autophagy can be related to fluctuations in gene expression, depending on the cell line investigated. ULK1 expression level was even still significantly higher $24 \mathrm{~h}$ after sorting in Aut ${ }^{\mathrm{HI}}$ relative to Aut $^{\mathrm{ME}}$ and Aut ${ }^{\mathrm{LO}}$, thus matching still stronger autophagy in Aut ${ }^{\mathrm{HI}}$ after this period. The homogenous ULK1 expression in sorted Jurkat cells, however, shows that ULK1 expression heterogeneity is not a necessary precondition for cell-to-cell variations in autophagy. In any case, the Cyto-ID intensity-correlated abundance of ULK1 mRNA in MOLM-13 cells in addition further support the validity of cell sorting on the basis of Cyto-ID.

Our second remarkable finding was the clear association of autophagic and metabolic activity. Cancer cells often have elevated levels of constitutive autophagy thought to provide the metabolic building blocks, such as amino acids and lipids, required for proliferation [62-64]. We found lowest basal respiration and lowest ATP production as well as lowest baseline glycolysis in Aut ${ }^{\mathrm{LO}}$ and, vice versa, highest bioenergetics parameters in Aut ${ }^{\mathrm{HI}}$. These data are thus in keeping with the ability of autophagy to fuel the metabolism - both oxidative metabolism and aerobic glycolysis - of cancer cells. Yet they are also compatible with a reciprocal interrelation between autophagy and metabolism, with the latter governing the former [72] (which would imply that the cell-to-cell fluctuations in basal autophagy were a consequence of cell-to-cell fluctuations in metabolism). That said, a bidirectional relationship between autophagy and metabolism is conceivable, too. In any case, our results support the tightly coordinated action of autophagy and metabolism [62-64].

Finally, cell cycle analysis of Cyto-ID-sorted cells confirmed that the fraction with highest autophagy was predominantly present in the $\mathrm{G} 2 / \mathrm{M}$ phase, a result that was further corroborated by gene and protein expression analyses of $\mathrm{G} 2 / \mathrm{M}$ markers in sorted cells.

\section{Conclusions}

To sum up, we have here provided clear evidence of high autophagy in G2/M phase cells. We have accomplished that by establishing two new Cyto-ID-based methods, in particular Cyto-ID-based cell 
sorting. A promising next step in the understanding of the interaction of autophagy and cell cycle would be to explore what these results could mean for the therapeutic targeting of autophagy in cancer.

\section{Abbreviations}

3-MA: $\quad$ 3-methyladenine

ATG: autophagy-related

Aut ${ }^{\mathrm{HI}}$ : cells with high autophagy

Aut ${ }^{\mathrm{LO}}$ : $\quad$ cells with low autophagy

Aut ${ }^{\mathrm{ME}}$ : $\quad$ cells with medium autophagy

CDK: $\quad$ cyclin-dependent kinase

CQ: $\quad$ chloroquine

ECAR: $\quad$ extracellular acidification rate

FSC-A: forward light scatter area

FSC-H: $\quad$ forward light scatter hight

FSC-W: forward light scatter width

IFM: indicator-free medium

OCR: oxygen consumption rate

PI: $\quad$ propidium iodide

SSC-A: $\quad$ sideward light scatter area

SSC-H: sideward light scatter height

SSC-W sideward light scatter width

\section{Declarations}

\section{Ethics approval and consent to participate}

Not applicable.

Consent for publication 
Not applicable.

\section{Availability of data and materials}

All data generated or analyzed during this study are included in this article and its supporting information files.

\section{Competing interests}

The authors declare that they have no competing interests.

\section{Funding}

MDJ received a fellowship from the "IZKF des Universitätsklinikum Jena". LMB received a fellowship from the Graduate Academy of the Friedrich Schiller University Jena.

\section{Authors' contributions}

The study conception and design were done by AG, CM, JFB. and JS. Material preparation and data collection were performed by AG, CM, MDJ, PS, HB, LMB, SB, LR and MR. Data were analyzed and interpreted by AG, CM, MDJ, PS, HB, LR, JFB and JS. The first draft of the manuscript was written by JS, and all authors commented on previous versions of the manuscript. All authors read and approved the final manuscript.

\section{Acknowledgements}

Not applicable.

\section{References}

1. Levine B, Kroemer G. Biological functions of autophagy genes: a disease perspective. Cell. 2019;176:11-42. https://doi.org/10.1016/j.cell.2018.09.048.

2. Mizushima N, Levine B. Autophagy in human diseases. N Engl J Med. 2020;383:1564-76. https://doi.org/10.1056/NEJMra2022774.

3. Klionsky DJ, Petroni G, Amaravadi RK, Baehrecke EH, Ballabio A, Boya P et al. Autophagy in major human diseases. EMBO J. 2021:e108863. https://doi.org/10.15252/embj.2021108863.

4. Dikic l, Elazar Z. Mechanism and medical implications of mammalian autophagy. Nat Rev Mol Cell Biol. 2018;19:349-64. https://doi.org/10.1038/s41580-018-0003-4.

5. Galluzzi L, Bravo-San Pedro JM, Levine B, Green DR, Kroemer G. Pharmacological modulation of autophagy: therapeutic potential and persisting obstacles. Nat Rev Drug Discov. 2017;16:487-511. https://doi.org/10.1038/nrd.2017.22. 
6. Levy JMM, Towers CG, Thorburn A. Targeting autophagy in cancer. Nat Rev Cancer. 2017;17:52842. https://doi.org/10.1038/nrc.2017.53.

7. Amaravadi RK, Kimmelman AC, Debnath J. Targeting autophagy in cancer: recent advances and future directions. Cancer Discov. 2019;9:1167-81. https://doi.org/10.1158/2159-8290.CD-19-0292.

8. Wang RC, Levine B. Autophagy in cellular growth control. FEBS Lett. 2010;584:1417-26. https://doi.org/10.1016/j.febslet.2010.01.009.

9. Neufeld TP. Autophagy and cell growth-the yin and yang of nutrient responses. J Cell Sci. 2012;125:2359-68. https://doi.org/10.1242/jcs.103333.

10. Mathiassen SG, De Zio D, Cecconi F. Autophagy and the cell cycle: a complex landscape. Front Oncol. 2017;7:51. https://doi.org/10.3389/fonc.2017.00051.

11. Zheng K, He Z, Kitazato K, Wang Y. Selective autophagy regulates cell cycle in cancer therapy. Theranostics. 2019;9:104-25. https://doi.org/10.7150/thno.30308.

12. Ben-Sahra I, Manning BD. mTORC1 signaling and the metabolic control of cell growth. Curr Opin Cell Biol. 2017;45:72-82. https://doi.org/10.1016/j.ceb.2017.02.012.

13. Szwed A, Kim E, Jacinto E. Regulation and metabolic functions of mTORC1 and mTORC2. Physiol Rev. 2021;101:1371-426. https://doi.org/10.1152/physrev.00026.2020.

14. Li Z, Zhang X. Kinases involved in both autophagy and mitosis. Int J Mol Sci. 2017;18:1884. https://doi.org/10.3390/ijms18091884.

15. Nowosad A, Jeannot P, Callot C, Creff J, Perchey RT, Joffre C et al. p27 controls Ragulator and mTOR activity in amino acid-deprived cells to regulate the autophagy-lysosomal pathway and coordinate cell cycle and cell growth. Nat Cell Biol. 2020;22:1076-90. https://doi.org/10.1038/s41556-020-0554-4.

16. Vijayaraghavan S, Karakas C, Doostan I, Chen X, Bui T, Yi M et al. CDK4/6 and autophagy inhibitors synergistically induce senescence in Rb positive cytoplasmic cyclin $\mathrm{E}$ negative cancers. Nat Commun. 2017;8:15916. https://doi.org/10.1038/ncomms15916.

17. Yin Q, Jian $Y, X u M$, Huang $X$, Wang $N$, Liu Z et al. CDK4/ 6 regulate lysosome biogenesis through TFEB/TFE3. J Cell Biol. 2020;219:e201911036. https://doi.org/10.1083/jcb.201911036.

18. Vessoni AT, Filippi-Chiela EC, Menck CF, Lenz G. Autophagy and genomic integrity. Cell Death Differ. 2013;20:1444-54. https://doi.org/10.1038/cdd.2013.103.

19. Roos WP, Thomas AD, Kaina B. DNA damage and the balance between survival and death in cancer biology. Nat Rev Cancer. 2016;16:20-33. https://doi.org/10.1038/nrc.2015.2. 
20. Hewitt G, Korolchuk VI. Repair, reuse, recycle: the expanding role of autophagy in genome maintenance. Trends Cell Biol. 2017;27:340-51. https://doi.org/10.1016/j.tcb.2016.11.011.

21. Gomes LR, Menck CFM, Leandro GS. Autophagy roles in the modulation of DNA repair pathways. Int J Mol Sci. 2017;18:2351. https://doi.org/10.3390/ijms18112351.

22. Kenzelmann Broz D, Spano Mello S, Bieging KT, Jiang D, Dusek RL, Brady CA et al. Global genomic profiling reveals an extensive p53-regulated autophagy program contributing to key p53 responses. Genes Dev. 2013;27:1016-31. https://doi.org/10.1101/gad.212282.112.

23. Kruiswijk F, Labuschagne CF, Vousden KH. p53 in survival, death and metabolic health: a lifeguard with a licence to kill. Nat Rev Mol Cell Biol. 2015;16:393-405. https://doi.org/10.1038/nrm4007.

24. Eskelinen EL, Prescott AR, Cooper J, Brachmann SM, Wang L, Tang X et al. Inhibition of autophagy in mitotic animal cells. Traffic. 2002;3:878-93. https://doi.org/10.1034/j.1600-0854.2002.31204.x.

25. Furuya T, Kim M, Lipinski M, Li J, Kim D, Lu T et al. Negative regulation of Vps34 by Cdk mediated phosphorylation. Mol Cell. 2010;38:500-11. https://doi.org/10.1016/j.molcel.2010.05.009.

26. Odle RI, Walker SA, Oxley D, Kidger AM, Balmanno K, Gilley R et al. An mTORC1-to-CDK1 switch maintains autophagy suppression during mitosis. Mol Cell. 2020;77:228-40. https://doi.org/10.1016/j.molcel.2019.10.016.

27. Tasdemir E, Maiuri MC, Tajeddine N, Vitale I, Criollo A, Vicencio JM et al. Cell cycle-dependent induction of autophagy, mitophagy and reticulophagy. Cell Cycle. 2007;6:2263-7. https://doi.org/10.4161/cc.6.18.4681.

28. Kang KB, Zhu C, Yong SK, Gao Q, Wong MC. Enhanced sensitivity of celecoxib in human glioblastoma cells: induction of DNA damage leading to p53-dependent G1 cell cycle arrest and autophagy. Mol Cancer. 2009;8:66. https://doi.org/10.1186/1476-4598-8-66.

29. Wang Y, Xu W, Yan Z, Zhao W, Mi J, Li J et al. Metformin induces autophagy and G0/G1 phase cell cycle arrest in myeloma by targeting the AMPK/mTORC1 and mTORC2 pathways. J Exp Clin Cancer Res. 2018;37:63. https://doi.org/10.1186/s13046-018-0731-5.

30. Yu H, Yin S, Zhou S, Shao Y, Sun J, Pang X et al. Magnolin promotes autophagy and cell cycle arrest via blocking LIF/Stat3/Mcl-1 axis in human colorectal cancers. Cell Death Dis. 2018;9:702. https://doi.org/10.1038/s41419-018-0660-4.

31. Kaluzki I, Hailemariam-Jahn T, Doll M, Kaufmann R, Balermpas P, Zöller N et al. Dimethylfumarate inhibits colorectal carcinoma cell proliferation: evidence for cell cycle arrest, apoptosis and autophagy. Cells. 2019;8:1329. https://doi.org/10.3390/cells8111329. 
32. Liu L, Xie R, Nguyen S, Ye M, McKeehan WL. Robust autophagy/mitophagy persists during mitosis. Cell Cycle. 2009;8:1616-20. https://doi.org/10.4161/cc.8.10.8577.

33. Domenech E, Maestre C, Esteban-Martinez L, Partida D, Pascual R, Fernandez-Miranda G et al. AMPK and PFKFB3 mediate glycolysis and survival in response to mitophagy during mitotic arrest. Nat Cell Biol. 2015;17:1304-16. https://doi.org/10.1038/ncb3231.

34. Li Z, Ji X, Wang D, Liu J, Zhang X. Autophagic flux is highly active in early mitosis and differentially regulated throughout the cell cycle. Oncotarget. 2016;7:39705-18. https://doi.org/10.18632/oncotarget.9451.

35. Li Z, Tian X, Ji X, Wang J, Chen H, Wang D et al. ULK1-ATG13 and their mitotic phospho-regulation by CDK1 connect autophagy to cell cycle. PLoS Biol. 2020;18:e3000288. https://doi.org/10.1371/journal.pbio.3000288.

36. Kuo PL, Hsu YL, Cho CY. Plumbagin induces G2-M arrest and autophagy by inhibiting the AKT/mammalian target of rapamycin pathway in breast cancer cells. Mol Cancer Ther. 2006;5:3209-21. https://doi.org/10.1158/1535-7163.MCT-06-0478.

37. Filippi-Chiela EC, Villodre ES, Zamin LL, Lenz G. Autophagy interplay with apoptosis and cell cycle regulation in the growth inhibiting effect of resveratrol in glioma cells. PLoS One. 2011;6:e20849. https://doi.org/10.1371/journal.pone.0020849.

38. Chen K, Shou LM, Lin F, Duan WM, Wu MY, Xie X et al. Artesunate induces G2/M cell cycle arrest through autophagy induction in breast cancer cells. Anticancer Drugs. 2014;25:652-62. https://doi.org/10.1097/CAD.0000000000000089.

39. Pathania AS, Guru SK, Kumar S, Kumar A, Ahmad M, Bhushan S et al. Interplay between cell cycle and autophagy induced by boswellic acid analog. Sci Rep. 2016;6:33146. https://doi.org/10.1038/srep33146.

40. Liang N, Liu X, Zhang S, Sun H. The role of Beclin 1 in IR-induced crosstalk between autophagy and G2/M cell cycle arrest. Cell Signal. 2019;62:109353. https://doi.org/10.1016/j.cellsig.2019.109353.

41. Huang R, Gao S, Han Y, Ning H, Zhou Y, Guan H et al. BECN1 promotes radiation-induced G2/M arrest through regulation CDK1 activity: a potential role for autophagy in G2/M checkpoint. Cell Death Discov. 2020;6:70. https://doi.org/10.1038/s41420-020-00301-2.

42. Sarraf SA, Sideris DP, Giagtzoglou N, Ni L, Kankel MW, Sen A et al. PINK1/Parkin influences cell cycle by sequestering TBK1 at damaged mitochondria, inhibiting mitosis. Cell Rep. 2019;29:225-35 e5. https://doi.org/10.1016/j.celrep.2019.08.085.

43. Kaminskyy V, Abdi A, Zhivotovsky B. A quantitative assay for the monitoring of autophagosome accumulation in different phases of the cell cycle. Autophagy. 2011;7:83-90. 
https://doi.org/10.4161/auto.7.1.13893.

44. Chan LL, Shen D, Wilkinson AR, Patton W, Lai N, Chan E et al. A novel image-based cytometry method for autophagy detection in living cells. Autophagy. 2012;8:1371-82. https://doi.org/10.4161/auto.21028.

45. Oeste CL, Seco E, Patton WF, Boya P, Perez-Sala D. Interactions between autophagic and endolysosomal markers in endothelial cells. Histochem Cell Biol. 2013;139:659-70. https://doi.org/10.1007/s00418-012-1057-6.

46. Guo S, Liang Y, Murphy SF, Huang A, Shen H, Kelly DF et al. A rapid and high content assay that measures cyto-ID-stained autophagic compartments and estimates autophagy flux with potential clinical applications. Autophagy. 2015;11:560-72. https://doi.org/10.1080/15548627.2015.1017181.

47. Zhao H, Traganos F, Dobrucki J, Wlodkowic D, Darzynkiewicz Z. Induction of DNA damage response by the supravital probes of nucleic acids. Cytometry A. 2009;75:510-9. https://doi.org/10.1002/cyto.a.20727.

48. Montecucco A, Zanetta F, Biamonti G. Molecular mechanisms of etoposide. EXCLI J. 2015;14:95108. https://doi.org/10.17179/excli2015-561.

49. Clifford B, Beljin M, Stark GR, Taylor WR. G2 arrest in response to topoisomerase II inhibitors: the role of p53. Cancer Res. 2003;63:4074-81.

50. Schonn I, Hennesen J, Dartsch DC. Cellular responses to etoposide: cell death despite cell cycle arrest and repair of DNA damage. Apoptosis. 2010;15:162-72. https://doi.org/10.1007/s10495-009-04409 .

51. Shimizu S, Kanaseki T, Mizushima N, Mizuta T, Arakawa-Kobayashi S, Thompson CB et al. Role of Bcl-2 family proteins in a non-apoptotic programmed cell death dependent on autophagy genes. Nat Cell Biol. 2004;6:1221-8. https://doi.org/10.1038/ncb1192.

52. Nishida Y, Arakawa S, Fujitani K, Yamaguchi H, Mizuta T, Kanaseki T et al. Discovery of Atg5/Atg7independent alternative macroautophagy. Nature. 2009;461:654-8. https://doi.org/10.1038/nature08455.

53. Kaizuka T, Morishita H, Hama Y, Tsukamoto S, Matsui T, Toyota $Y$ et al. An autophagic flux probe that releases an internal control. Mol Cell. 2016;64:835-49. https://doi.org/10.1016/j.molcel.2016.09.037.

54. Huang HL, Hsing HW, Lai TC, Chen YW, Lee TR, Chan HT et al. Trypsin-induced proteome alteration during cell subculture in mammalian cells. J Biomed Sci. 2010;17:36. https://doi.org/10.1186/14230127-17-36.

55. Cheng J, Haas M. Frequent mutations in the p53 tumor suppressor gene in human leukemia T-cell lines. Mol Cell Biol. 1990;10:5502-9. https://doi.org/10.1128/mcb.10.10.5502. 
56. Kojima K, Konopleva M, Samudio IJ, Shikami M, Cabreira-Hansen M, McQueen T et al. MDM2 antagonists induce p53-dependent apoptosis in AML: implications for leukemia therapy. Blood. 2005;106:3150-9. https://doi.org/10.1182/blood-2005-02-0553.

57. Klionsky DJ, Abdel-Aziz AK, Abdelfatah S, Abdellatif M, Abdoli A, Abel S et al. Guidelines for the use and interpretation of assays for monitoring autophagy (4th edition). Autophagy. 2021:1-382. https://doi.org/10.1080/15548627.2020.1797280.

58. Sherr CJ, Beach D, Shapiro GI. Targeting CDK4 and CDK6: from discovery to therapy. Cancer Discov. 2016;6:353-67. https://doi.org/10.1158/2159-8290.CD-15-0894.

59. Füllgrabe J, Klionsky DJ, Joseph B. The return of the nucleus: transcriptional and epigenetic control of autophagy. Nat Rev Mol Cell Biol. 2014;15:65-74. https://doi.org/10.1038/nrm3716.

60. Füllgrabe J, Ghislat G, Cho DH, Rubinsztein DC. Transcriptional regulation of mammalian autophagy at a glance. J Cell Sci. 2016;129:3059-66. https://doi.org/10.1242/jcs.188920.

61. Bordi M, De Cegli R, Testa B, Nixon RA, Ballabio A, Cecconi F. A gene toolbox for monitoring autophagy transcription. Cell Death Dis. 2021;12:1044. https://doi.org/10.1038/s41419-021-04121-9.

62. Galluzzi L, Pietrocola F, Levine B, Kroemer G. Metabolic control of autophagy. Cell. 2014;159:126376. https://doi.org/10.1016/j.cell.2014.11.006.

63. Kimmelman AC, White E. Autophagy and tumor metabolism. Cell Metab. 2017;25:1037-43. https://doi.org/10.1016/j.cmet.2017.04.004.

64. Lahiri V, Hawkins WD, Klionsky DJ. Watch what you (self-) eat: autophagic mechanisms that modulate metabolism. Cell Metab. 2019;29:803-26. https://doi.org/10.1016/j.cmet.2019.03.003.

65. Ferrick DA, Neilson A, Beeson C. Advances in measuring cellular bioenergetics using extracellular flux. Drug Discov Today. 2008;13:268-74. https://doi.org/10.1016/j.drudis.2007.12.008.

66. Williams GH, Stoeber K. Cell cycle markers in clinical oncology. Curr Opin Cell Biol. 2007;19:672-9. https://doi.org/10.1016/j.ceb.2007.10.005.

67. Warnes G. Flow cytometric assays for the study of autophagy. Methods. 2015;82:21-8. https://doi.org/10.1016/j.ymeth.2015.03.027.

68. Tasdemir E, Maiuri MC, Orhon I, Kepp O, Morselli E, Criollo A et al. p53 represses autophagy in a cell cycle-dependent fashion. Cell Cycle. 2008;7:3006-11. https://doi.org/10.4161/cc.7.19.6702.

69. Gump JM, Staskiewicz L, Morgan MJ, Bamberg A, Riches DW, Thorburn A. Autophagy variation within a cell population determines cell fate through selective degradation of Fap-1. Nat Cell Biol. 2014;16:47-54. https://doi.org/10.1038/ncb2886. 
70. Gump JM, Thorburn A. Sorting cells for basal and induced autophagic flux by quantitative ratiometric flow cytometry. Autophagy. 2014;10:1327-34. https://doi.org/10.4161/auto.29394.

71. Ben-David U, Siranosian B, Ha G, Tang H, Oren Y, Hinohara K et al. Genetic and transcriptional evolution alters cancer cell line drug response. Nature. 2018;560:325-30. https://doi.org/10.1038/s41586018-0409-3.

72. Thomas HE, Zhang Y, Stefely JA, Veiga SR, Thomas G, Kozma SC et al. Mitochondrial complex I activity is required for maximal autophagy. Cell Rep. 2018;24:2404-17. https://doi.org/10.1016/j.celrep.2018.07.101.

\section{Figures}




\section{Jurkat}
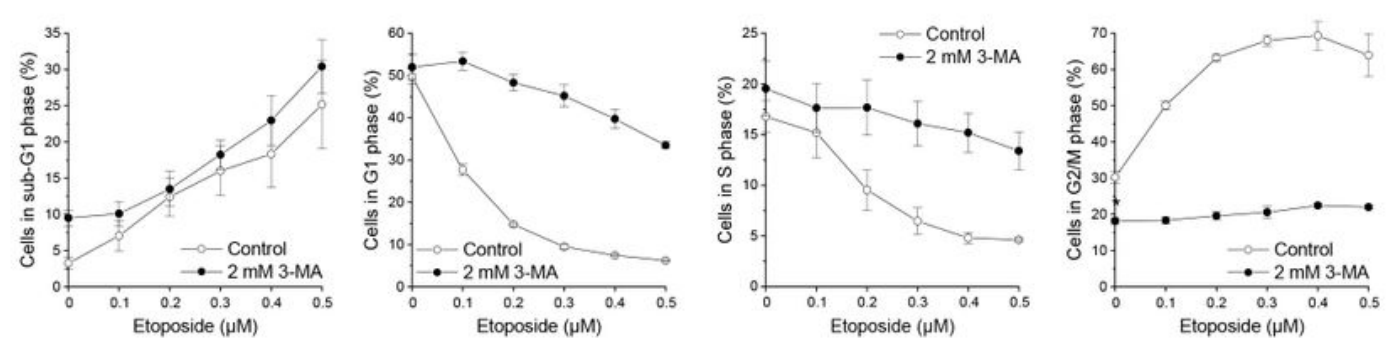

\section{MOLM-13}
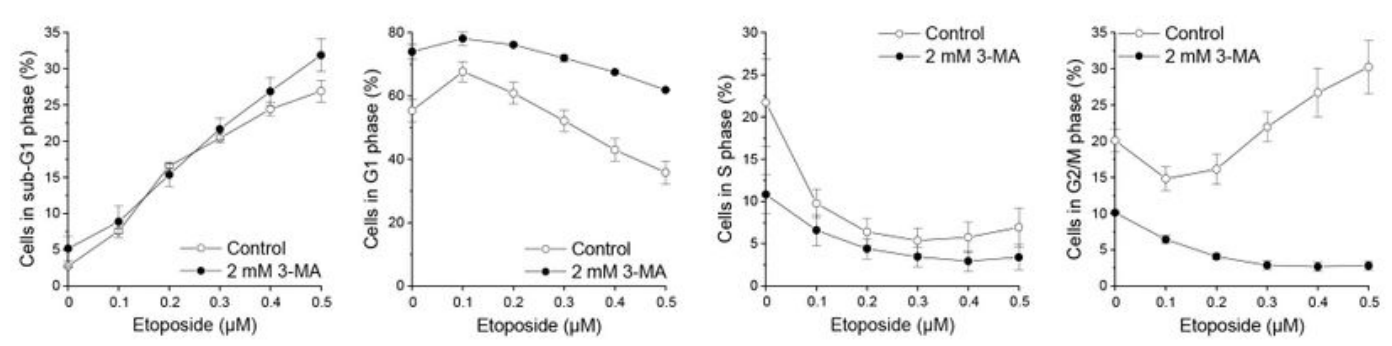

\section{Figure 1}

Autophagy inhibition affects etoposide-induced cell cycle arrest. Cells were exposed to etoposide with or without 3-MA for $48 \mathrm{~h}$. Cell cycle phases were determined by flow-cytometric analysis of PI-stained ethanol-fixed cells. Means \pm SEM of each three separate measurements are shown. 
A
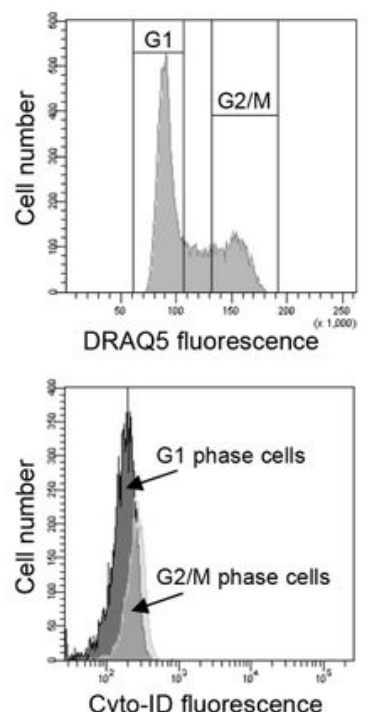

B

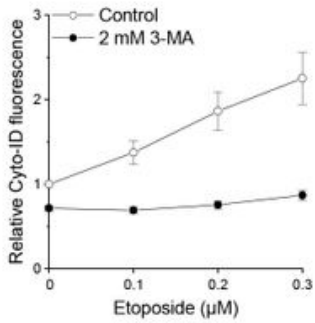

Jurkat

C

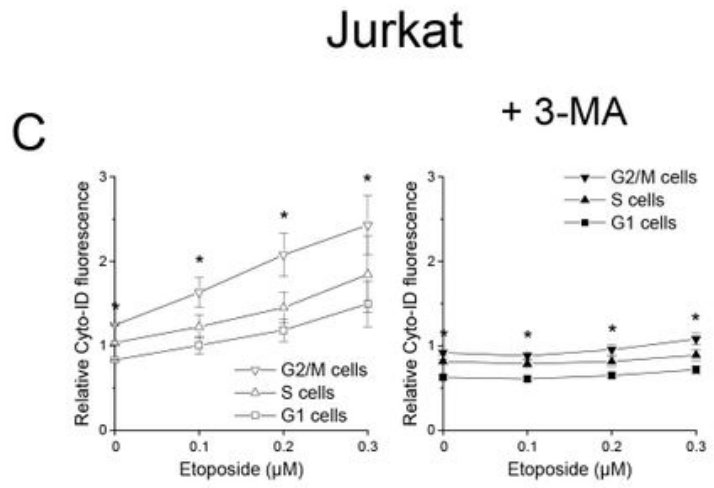

Jurkat

MOLM-13
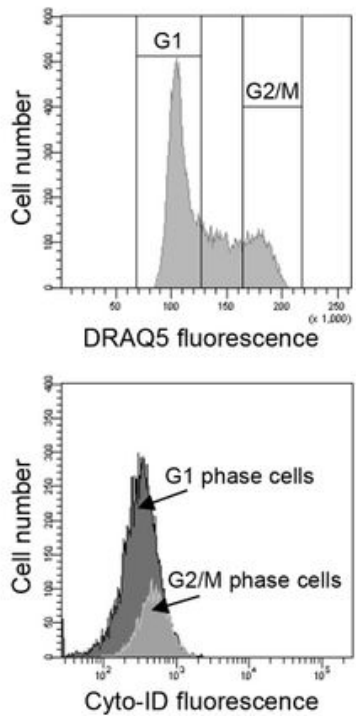

MOLM-13

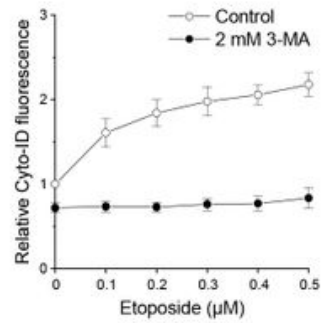

MOLM-13

+ 3-MA
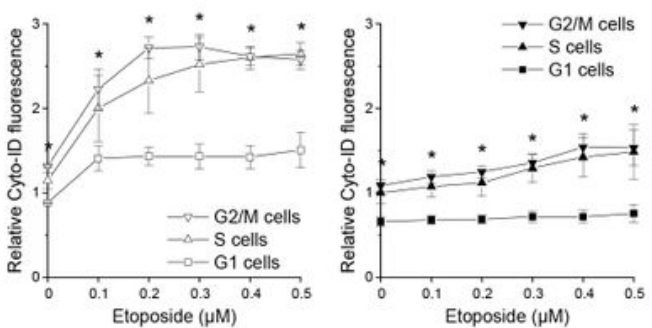

\section{Figure 2}

G2/M phase cells have higher autophagy than G1 phase cells. Autophagy and cell cycle phases were determined by flow-cytometric analysis of Cyto-ID + DRAQ5 double-stained cells. (A) Representative histograms of untreated cells. $(B-C)$ Cells were exposed to etoposide with or without 3-MA for $24 \mathrm{~h}$ (Jurkat) or $48 \mathrm{~h}$ (MOLM-13). Cyto-ID fluorescence intensities were normalized to the mean Cyto-ID 
fluorescence intensities of untreated cells. Means \pm SEM of each three separate measurements are shown ( $\mathrm{G} 1$ cells versus $\mathrm{G} 2 / \mathrm{M}$ cells: $\mathrm{P}<0.05)$.

Figure 3
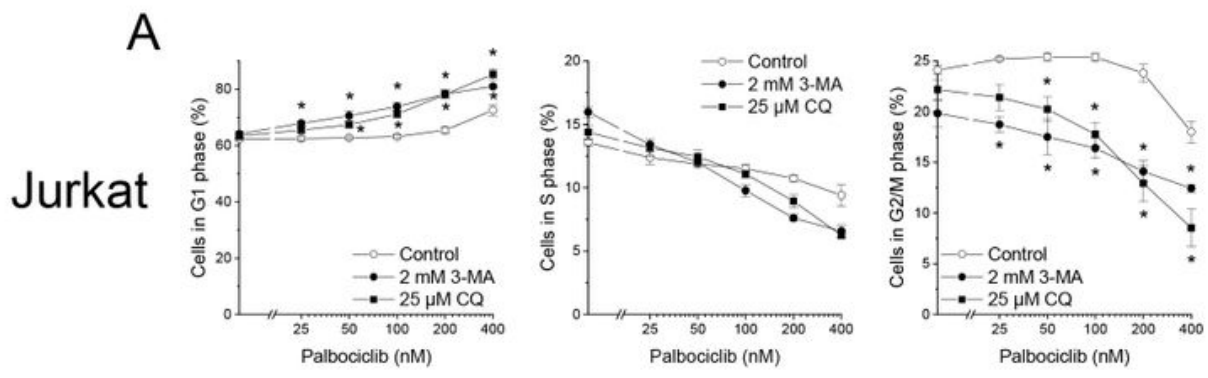

MOLM-13
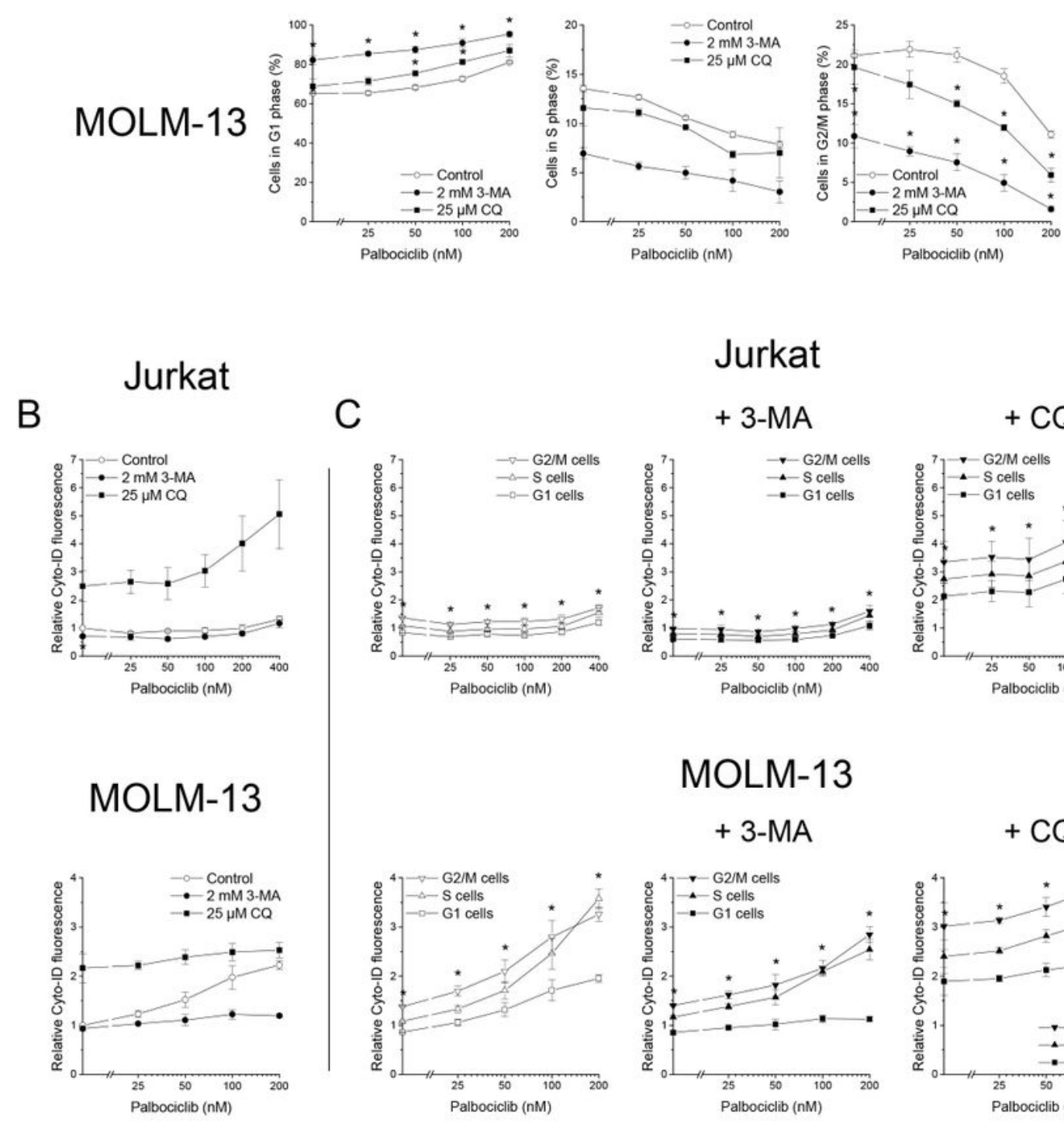

Jurkat

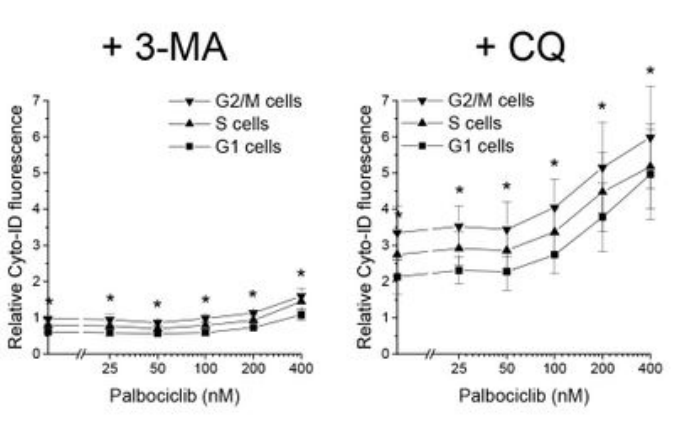

\section{MOLM-13}
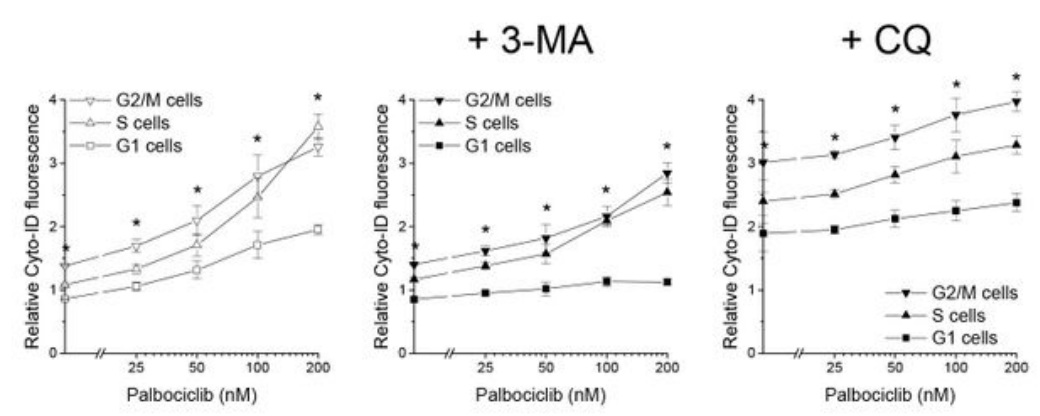

\section{Figure 3}

Autophagy inhibition enhances palbociclib-induced G1 phase arrest. Cells were exposed to palbociclib with or without autophagy inhibitors for $48 \mathrm{~h}$. Autophagy and cell cycle phases were determined by flowcytometric analysis of Cyto-ID + DRAQ5 double-stained cells. (A) Effect of palbociclib on cell cycle 
distribution. (B-C) Effect of palbociclib on autophagy. Cyto-ID fluorescence intensities were normalized to the mean Cyto-ID fluorescence intensities of untreated cells. Means \pm SEM of each three separate measurements are shown (A: 3-MA or CQ versus control, C: G1 cells versus G2/M cells: *P < 0.05 ).

\section{Figure 4}

\section{Jurkat}

A
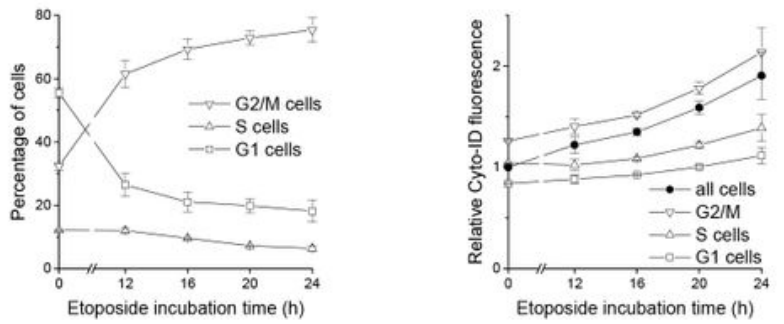

B

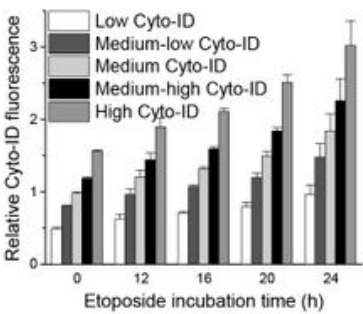

C
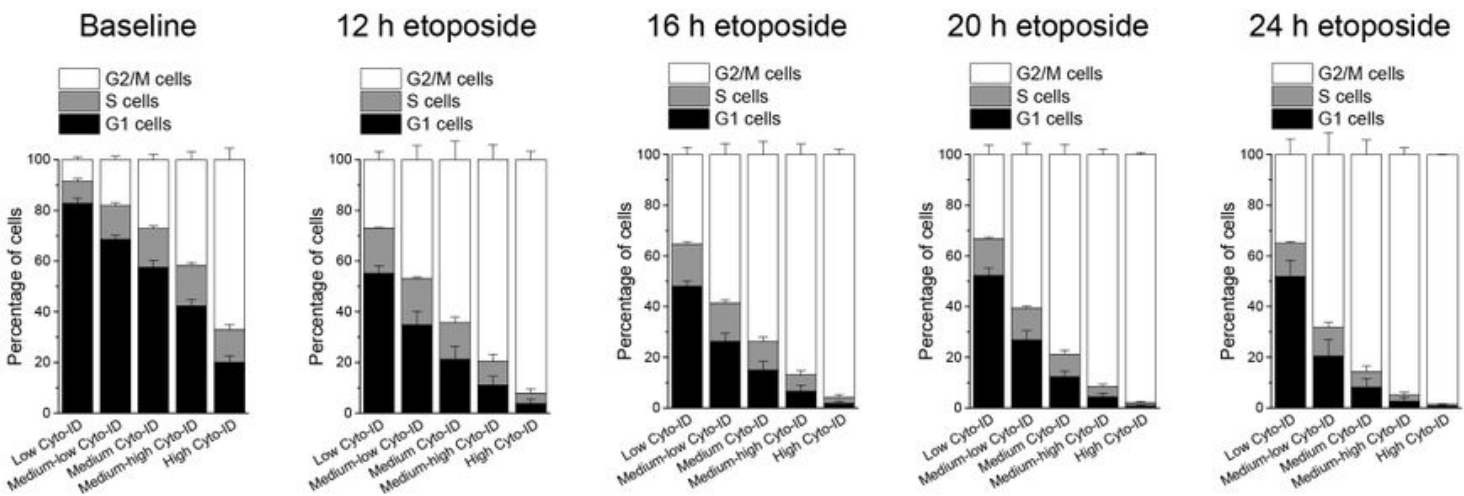

Figure 4

Cell cycle phase and autophagy are tightly associated. Cells were exposed to $0.2 \mu \mathrm{M}$ etoposide for the indicated times. Autophagy and cell cycle phases were determined by flow-cytometric analysis of Cyto-ID 
+ DRAQ5 double-stained cells. (A) Effect of etoposide on cell cycle phase distribution and autophagy. (BC) Cell populations were grouped into quintiles based on their Cyto-ID fluorescence intensities (see Figure S3A). (B) Relative Cyto-ID fluorescence intensities of the quintiles of cells. Cyto-ID fluorescence intensities were normalized to the mean Cyto-ID fluorescence intensity of untreated cells. (C) Cell cycle phase distribution in the quintiles of cells. Means \pm SEM of two (12-h and 16-h treatment) or three separate measurements are shown.

\section{Figure 5}

\section{Cyto-ID-sorted Jurkat}

A

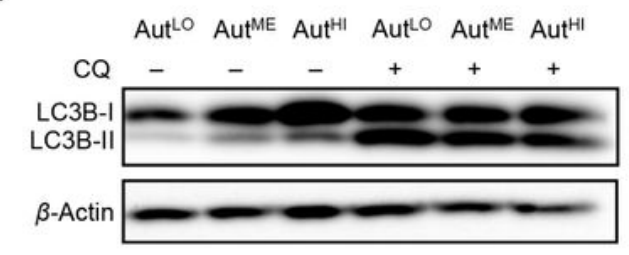

Cyto-ID-sorted Jurkat

B

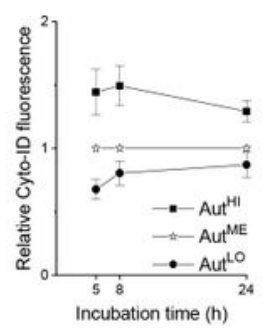

Cyto-ID-sorted Jurkat

C

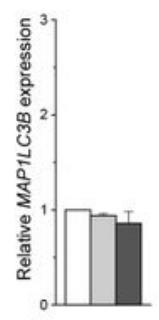

Cyto-ID-sorted MOLM-13

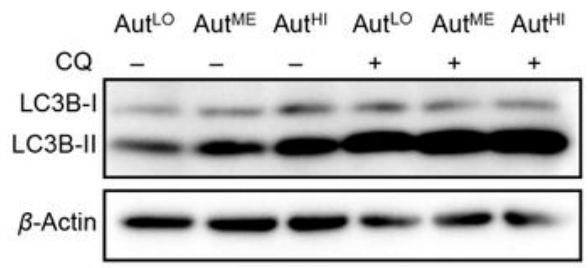

Cyto-ID-sorted MOLM-13

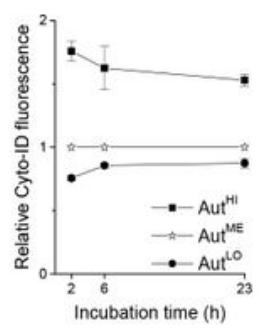

Cyto-ID-sorted MOLM-13

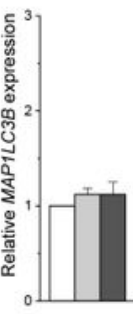

D

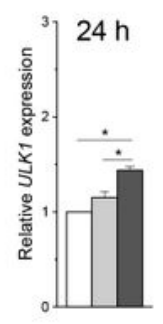


Cyto-ID-sorted cells display different autophagy levels over at least $24 \mathrm{~h}$. Cells were flow-cytometrically sorted on the basis of their Cyto-ID fluorescence intensity into subpopulations with low, medium and high Cyto-ID fluorescence (AutLO, AutME and AutHI, respectively). (A) Representative immunoblots of lysates from sorted cells. Lysates were prepared after 1-h cultivation of sorted cells in the absence or presence of $10 \mu \mathrm{M}$ CQ. (B) Sorted cells were incubated for the indicated times, and autophagy was determined by flow-cytometric analysis of Cyto-ID-stained cells. Cyto-ID fluorescence intensities of the three fractions were normalized to the Cyto-ID fluorescence intensity of AutME. (C-D) RNA was prepared either approximately $1 \mathrm{~h}$ after sorting (C) or after a 24-h cultivation of sorted cells (D). mRNA expression levels were determined by real-time RT-PCR and normalized to B2M expression levels. Means \pm SEM of three $(C-D)$ or four $(B)$ separate measurements are shown ( $\left.{ }^{\star} P<0.05\right)$. 


\section{Figure 6}

Cyto-ID-sorted Jurkat

A

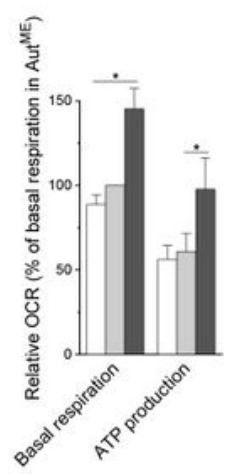

Cyto-ID-sorted Jurkat

B

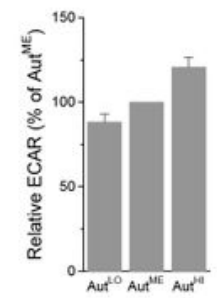

\section{Cyto-ID-sorted Jurkat}

C

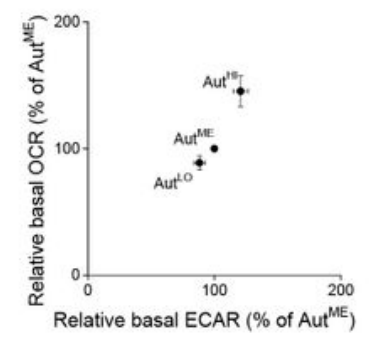

Cyto-ID-sorted MOLM-13

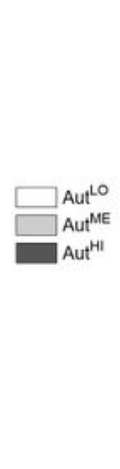

Cyto-ID-sorted MOLM-13

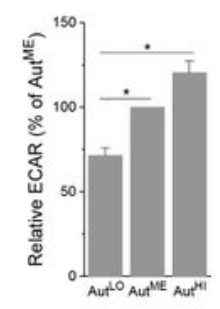

\section{Cyto-ID-sorted MOLM-13}

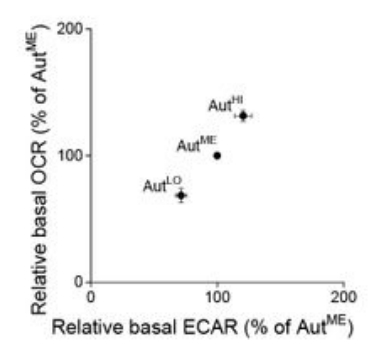

\section{Figure 6}

Autophagic and metabolic activities are associated. Cells were flow-cytometrically sorted on the basis of their Cyto-ID fluorescence intensity into subpopulations with low, medium and high Cyto-ID fluorescence (AutLO, AutME and AutHI, respectively). The subpopulations were subjected to metabolic analysis immediately after sorting. (A) OCR as a proxy for oxidative metabolism was measured with a Seahorse XFe96 Analyzer using a Cell Mito Stress Test. ATP production was calculated from OCR data (see Figure 
S6 for details). (B) ECAR was measured as a proxy for glycolytic activity. OCR and ECAR of the three fractions were normalized to OCR and ECAR of AutME. (C) Energetic maps of sorted cells generated from $\mathrm{OCR}$ and ECAR data presented in A and B, respectively. Means \pm SEM of each three separate measurements are shown; each biological replicate consisted of six readings ( $\left.{ }^{*} P<0.05\right)$.

\section{Figure 7}

\section{Cyto-ID-sorted Jurkat Cyto-ID-sorted MOLM-13}

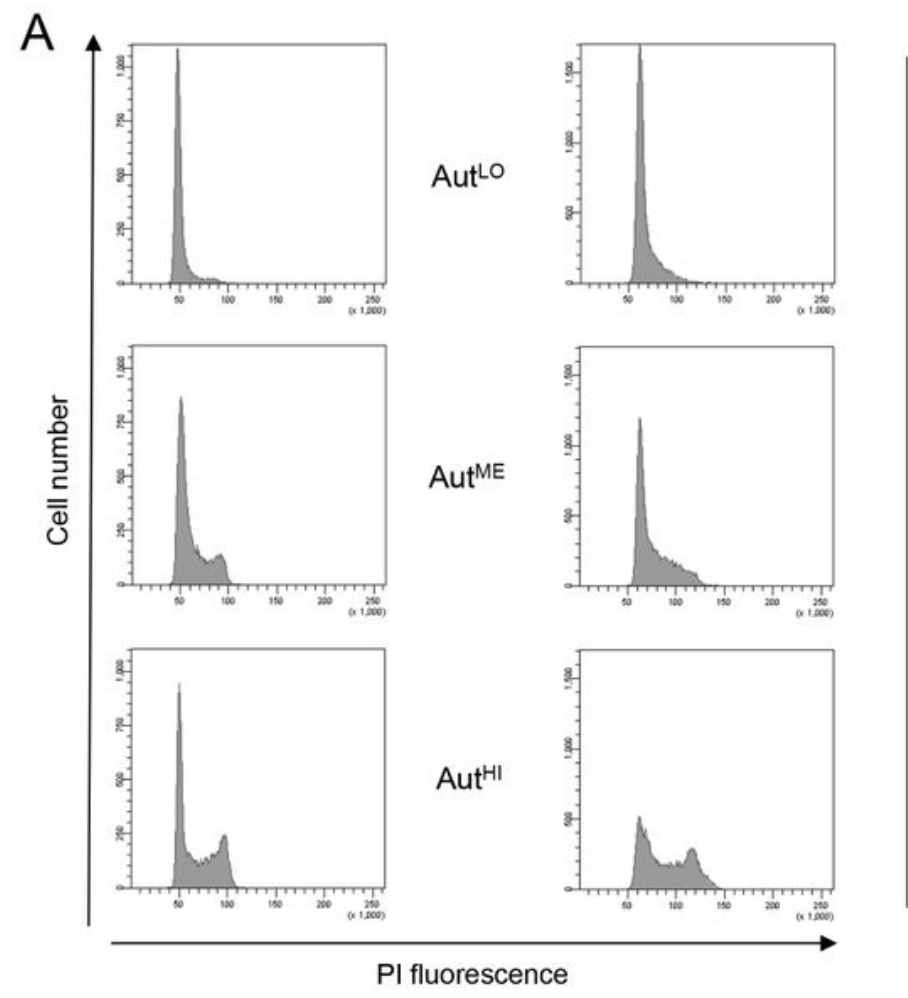

B

\section{Cyto-ID-sorted Jurkat}

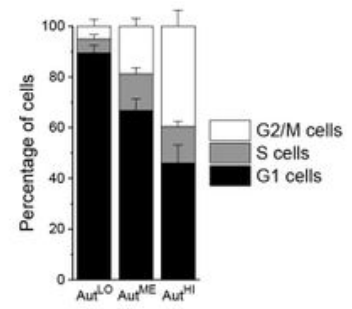

\section{Cyto-ID-sorted MOLM-13}

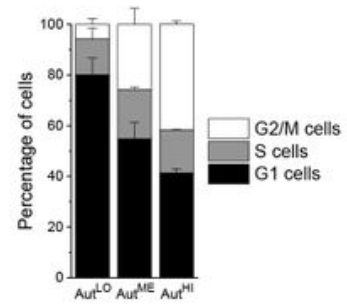

Cyto-ID-sorted Jurkat

C
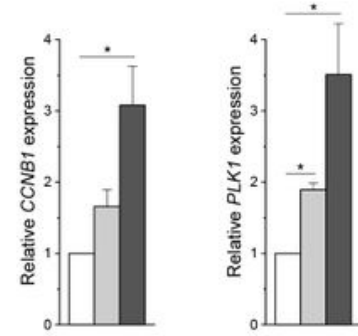

D

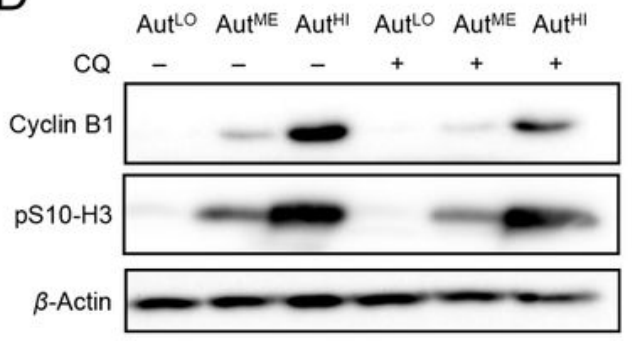

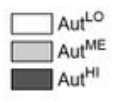

Cyto-ID-sorted MOLM-13
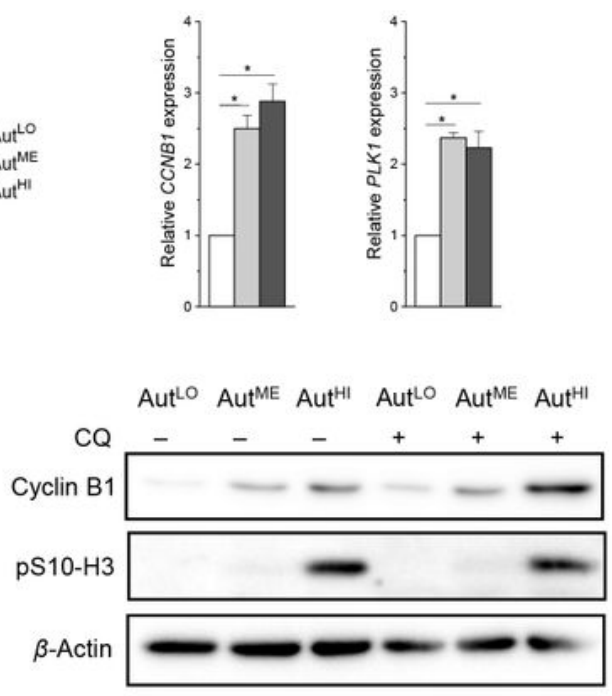

Figure 7 
Cells with high autophagy are preferentially in the G2/M phase of the cell cycle. Cells were flowcytometrically sorted on the basis of their Cyto-ID fluorescence intensity into subpopulations with low, medium and high Cyto-ID fluorescence (AutLO, AutME and AutHI, respectively). (A-B) Cells were fixed in ethanol approximately $1 \mathrm{~h}$ after sorting. Cell cycle phases were determined by flow-cytometric analysis of Pl-stained ethanol-fixed cells. (A) Representative histograms of cell populations. (B) Quantification of cell cycle phases. (C) RNA was prepared approximately $1 \mathrm{~h}$ after sorting. mRNA expression levels were determined by real-time RT-PCR and normalized to B2M expression levels. Means \pm SEM of each three separate measurements are shown ( $\left.{ }^{\star} P<0.05\right)$. (D) Representative immunoblots of lysates from sorted cells. Lysates were prepared after a 1-h cultivation of sorted cells in the absence or presence of $10 \mu \mathrm{M} \mathrm{CQ}$. The loading controls are the same as in Figure 5A since LC3B, cyclin B1, pS10-H3 and $\beta$-actin were detected on the same blots.

\section{Supplementary Files}

This is a list of supplementary files associated with this preprint. Click to download.

- GschwindetalSupportingFigure1.pptx

- GschwindetalSupportingFigure2.pptx

- GschwindetalSupportingFigure3.pptx

- GschwindetalSupportingFigure4.pptx

- GschwindetalSupportingFigure5.pptx

- GschwindetalSupportingFigure6.pptx

- GschwindetalSupportingFigure7.pptx 